\title{
]jfis
}

\section{Development of a Prototype Data Logger System to Operate under Extreme High Pressure}

\author{
Nam-Hyun $\mathrm{Yoo}^{1}$, Sang-Yong Rhee ${ }^{2}$, and Hyeong-Ok Lee ${ }^{3}$ \\ ${ }^{1}$ Department of Naval Architecture, Ocean and IT Engineering, Kyungnam University, Changwon, Korea \\ ${ }^{2}$ Division of Computer Science and Engineering, Kyungnam University, Changwon, Korea \\ ${ }^{3}$ Department of Computer Education, Sunchon National University, Suncheon, Korea
}

Received: Jun. 3, 2014

Revised : Jun. 24, 2014

Accepted: Jun. 24, 2014

Correspondence to: Hyeong-Ok Lee (oklee@sunchon.ac.kr)

(T) The Korean Institute of Intelligent Systems

@CThis is an Open Access article distributed under the terms of the Creative Commons Attribution Non-Commercial License (http://creativecommons.org/licenses/ by-nc/3.0// which permits unrestricted noncommercial use, distribution, and reproduction in any medium, provided the original work is properly cited.

\begin{abstract}
A subsea oil production system must be safely operated for 20-30 years after being installed. Because of the severe conditions of the subsea environment, such as extreme high pressure, low visibility, the possibility of unexpected impact by any object, and corrosion by seawater, subsea oil production systems should be monitored by subsea data logger systems and remotely operated vehicles to check for abnormal vibration and leakage to prevent a catastrophic accident. Because of the severity of subsea environmental conditions and the dominance of a few companies in the market, many people have thought that it would be difficult to develop a subsea data logger system. The primary objectives of the study described in this paper were to analyze existing subsea data logger systems to establish the requirements for a subsea data logger system, implement a prototype subsea data logger system, and conduct a test of the prototype subsea data logger system.
\end{abstract}

Keywords: Data logger system, Subsea, Inspection repair and maintenance, Extreme high pressure, Embedded system

\section{Introduction}

Recently, several traditional major oil companies, such as British Petroleum (BP), Royal Dutch Shell, Exxon Mobil, and Chevron, have exploited oil from onshore, offshore, and subsea areas because the total amount of oil obtained from sources on land has not been able to meet the demand for oil, which for dozens of years has been growing in developing countries such as China, India, and others. As the technology for drilling develops and oil prices rise to more than $\$ 100$ per a barrel, oil wells in onshore, offshore, and especially subsea areas are becoming more productive for oil companies. Because of the emergence of new areas for exploiting oil, new oil-producing countries such as Brazil, Malaysia, Indonesia, Nigeria, Angola, and others are playing larger roles in the global oil market. The exploitation of subsea areas for oil production is particularly challenging and interesting to scientists and engineers because of the extreme high pressure conditions. In addition, oil wells in subsea areas are attractive to oil major oil companies because the total amount of oil from oil wells in subsea areas that have already been discovered is greater than the amount of oil available from existing oil wells on land.

Since 2003, when ChevronTexaco (Chevron) succeeded in drilling oil wells located in 
Toledo in the Gulf of Mexico at a depth of approximately $3,052 \mathrm{~m}$ [1], many oil wells in subsea areas have been drilled and exploited. Because of the environmental restrictions that exist in subsea areas, a subsea oil production system must be able to resist extreme high pressure and seawater. In addition, it is not easy to access most oil wells locate at depths between 1,000 and 2,000 $\mathrm{m}$. Thus, many organizations, such as the American Petroleum Institute (API), the American Bureau of Shipping (ABS), and Det Norske Veritas (DNV), have established and enforced rules for relevant companies to ensure the safety of subsea oil production systems. However, a tragic disaster occurred at the Macondo well, located in the Gulf of Mexico, on April 20, 2010 [2]. This disaster brought about the deaths of 11 persons, tremendous property loss, and inestimable environmental damage by oil spills. According to a BP internal report, the causes of this disaster were complex. However, if the monitoring system for a subsea production system works well, the extent of the damage resulting from such a disaster can be reduced. Oil companies have recognized the importance of inspection, repair, and maintenance (IRM) and have invested considerable amounts of money in IRM to maintain existing subsea oil production systems.

According to [3], the market for subsea oil production systems is worth 300 billion dollars as of 2014. However, the market is very exclusive and is monopolized by a few companies [4]. However, the Korean government and many companies, including three large shipbuilding companies, have tried to manufacture relevant equipment. A subsea data logger system for IRM is one of several types of equipment that the Korean government and many companies want to put in place because this type of system is based on information technology (IT) and has fewer technical barriers than other types of equipment.

The primary objectives of this study were to (1) analyze existing subsea data logger systems, (2) establish requirements for subsea data logger systems, (3) implement a prototype subsea data logger system, (4) conduct a test of the prototype, and (5) demonstrate the feasibility of developing a subsea data logger system. The remainder of this paper is organized as follows. Section 2 describes related work. Section 3 describes the requirements for a subsea data logger system. Section 4 describes the process of implementing a prototype of a subsea data logger system. Section 5 presents conclusions.

\section{Related Work}

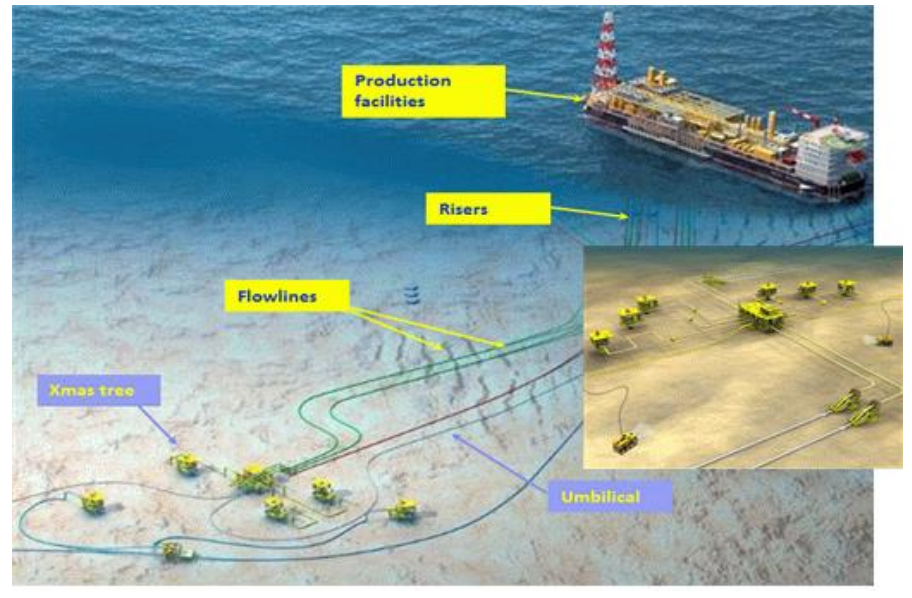

Figure 1. Overview of a subsea oil production system.

\subsection{Subsea Oil Production System}

A subsea oil production system is typically composed of an $\mathrm{X}$-mas tree, flowlines, risers, an umbilical, and production facilities. If there are many wells, a manifold can be added to a subsea oil production system. Figure 1 shows an overview of a subsea oil production system.

The X-mas tree is installed on the top of the oil well, which is called the wellhead. The X-mas tree regulates the production of oil and serves as part of the interface between the oil well and other equipment by providing a blow-out preventer (BOP). Sometimes, the X-mas tree becomes a passage by which chemical compounds are injected into the oil well or the flowlines, and sometimes it is used to control downhole valves. Additionally, the X-mas tree removes the excess pressure on the annulus and maintains a constant flow of oil through a choke. For these reasons, the $\mathrm{X}$-mas tree is an important piece of safety equipment [5]. Flowlines are installed between the $\mathrm{X}$-mas tree and risers or between the X-mas tree and a manifold. Flowlines are passages by which crude oil is moved the production facilities. Risers are installed between the X-mas tree or manifold and the production facilities. Risers push crude oil upward at high pressure. The umbilical, which is installed between the production facilities and the X-mas tree, is composed of cables and fiber optic cables and provides electrical power and hydraulic power. The X-mas tree, flowlines, risers, and manifold can be controlled through the umbilical [6]. Figure 2 shows a typical cross section of an umbilical. Production facilities are floating mass structures that produce various oil products from crude oil and provide storage for oil products until they are transferred to chemical carriers. Production facilities are usually called 


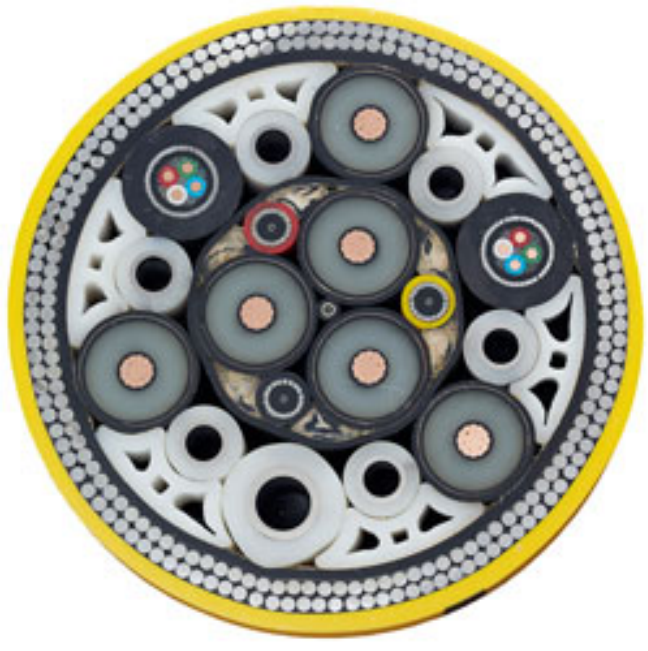

Figure 2. Typical cross section of an umbilical.

floating production storage and offloading (FPSOs).

\subsection{IRM and Subsea Data Logger System}

After subsea oil production systems are installed in subsea areas, these systems can be operated for 20-30 years to exploit crude oil. Thus, data loggers should be employed with subsea oil production systems. Data logger systems have been widely used to collect various types of data from the environment, sensors, and equipment [7-10]. However, data logger systems have not been widely used with subsea oil production systems because most experts have held the view that applying verified equipment and strict rules guarantees the safety of subsea production systems and that operation of subsea data logger systems and remotely operated vehicles (ROVs) for IRM result in additional operational costs. Actually, the rules related to subsea equipment for oil production systems are very strict, and only proven equipment can be applied to a subsea oil production system. For these complex reasons, the importance of IRM has been relatively little recognized, while subsea oil wells have been widely exploited.

Fortunately, many subsea data logger systems and ROVs have been installed to monitor subsea oil production systems since the disaster that happened in 2010. In addition, relevant markets are steadily growing. The main function of a subsea data logger system is to monitor abnormal vibrations and leakage under extreme conditions, such as strong seabed currents, low visibility, corrosion, and extreme high pressure. Among these environmental conditions, extreme high pressure is the most important concern in developing a subsea data logger system.

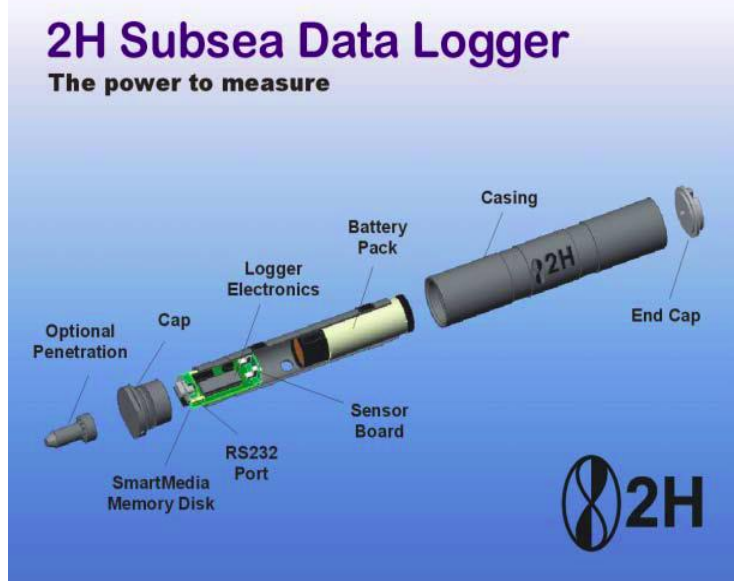

Figure 3. General architecture of a subsea data logger system.

A subsea data logger system is typically composed of a housing cap, a main body, a battery pack, a sensor board (or embedded system), a memory disk, and optional penetrated interfaces for the outer sensors, as in the $2 \mathrm{H}$ subsea data logger shown in Figure 3. Installation of a subsea data logger system on a riser using an ROV is shown in Figure 4.

\section{Requirements for a Subsea Data Logger Sys- tem}

We analyzed the top three existing brand products in the global markets to determine the requirements for a subsea data logger system. These products are typically installed and operated to maintain and monitor subsea production systems with ROVs. Based on this analysis, several significant requirements were established for the system to be developed.

First, a subsea data logger system needs robust material to protect an internal embedded system and connecting interfaces from extreme high pressure and corrosion by seawater for a minimum of 20-30 years. The candidate material for the case is austenitic type 316 stainless steel (SS). The properties of this material are shown in Table 1.

Austenitic 316 SS cannot completely prevent infiltration of seawater at extreme high pressure. Thus, a subsea data logger system needs O-rings and grease to seal the case, and these O-rings and grease should be tested to prove their performance. The case also needs interfaces to connect external sensors and cameras to an internal embedded system. In addition, these interfaces have to follow de facto rules. Each interface type is dependent on the types of sensors and cameras used. Table 2 
Table 1. Properties of austenitic 316 stainless steel (SS)

\begin{tabular}{lccl}
\hline Category & Representative type & Basic composition & \multicolumn{1}{c}{ Properties } \\
\hline Austenite & $304 \mathrm{SS}$ & $18 \mathrm{Cr} / 8 \mathrm{Ni}$ & No magnetism, excellent corrosion resistance \\
& $316 \mathrm{SS}$ & & High impact resistance, high elongation capacity \\
& & Not hardened by heat treatment \\
& & Restricted use under high temperature \\
& & \\
\end{tabular}

Table 2. Variable interfaces for connection to a subsea data logger system

\begin{tabular}{|c|c|c|c|c|}
\hline Type & & & & \\
\hline Properties & 3 pins & 4 pins & 5 pins & 8 pins \\
\hline Purpose & LED light & Sensors \& control & Sensors \& control & Cameras \\
\hline
\end{tabular}

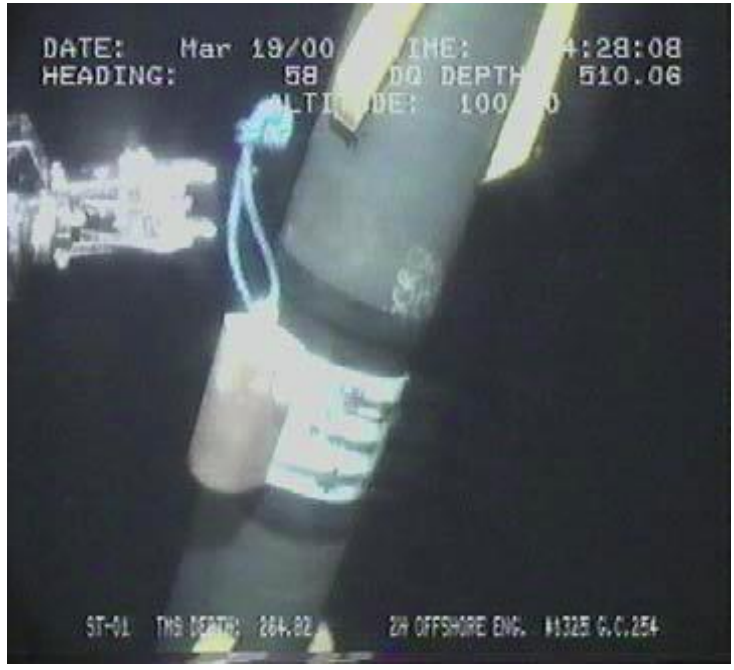

Figure 4. Installation of a subsea data logger system on a riser using an remotely operated vehicle..

shows the variable supporting interfaces to connect sensors and cameras to a subsea data logger system.

Second, an optimized embedded system has to be developed and installed inside a case with batteries. The most recently developed subsea data logger systems support wireless protocols. However, the system proposed in this paper does not support a wireless network at this time. The embedded system should have multiple analog channels to gather analog signals from the external sensors. To store these signals, the embedded system needs a converting device to transform analog signals into digi- tal signals. A subsea data logger system has to be installed on equipment suitable for subsea production systems. Thus, the power consumption of the system has to be low so that environmental data can be gathered from subsea production system equipment and stored for long periods of time.

Third, dedicated software should be provided with a subsea data logger system to extract data from the subsea data logger system. A subsea data logger installed on production equipment should usually be retrieved every half month to one month to extract data and change the internal batteries. The software has various packages for data logger group management, configuration management, battery management system, data export and import management, backup and recovery management, user account management, and auto report management. Figure 5 shows an overview of the software and a snapshot of the software interface provided by CDL Inertial Engineering.

\section{Development of the Prototype}

\subsection{Overview of the Prototype}

In general, the basic shape of a case for a subsea data logger system is a cylinder, which is stronger than a cube or a rectangular parallelepiped under extreme high pressure. In this study, an external case for a subsea data logger system was designed. The case is composed of a main body, a top housing cap, a bottom housing cap, and O-rings and is made of austenitic 316 SS. The top housing cap has four interfaces for external sensors. 


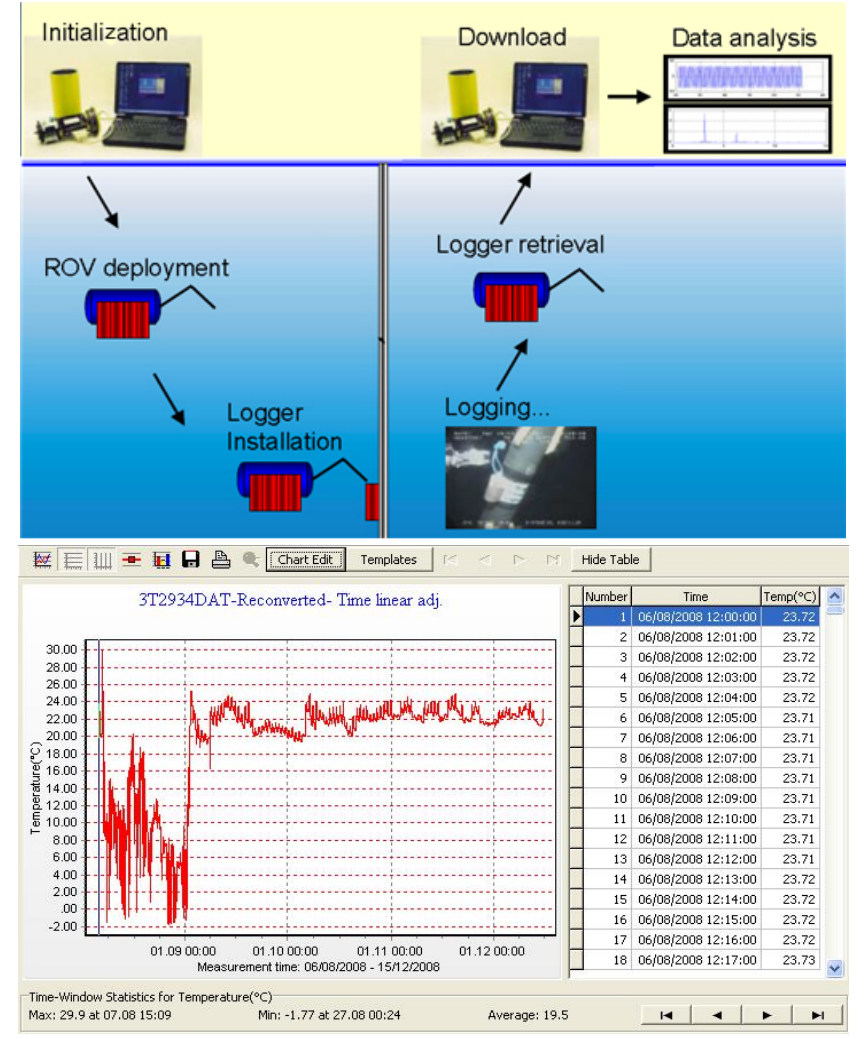

Figure 5. Overview of the integrated management software and a snapshot of the software interface provided by CDL Inertial Engineering.

In addition, the interfaces have O-rings and grease to seal gaps between the top housing cap and the main body. An embedded system and battery are arranged in the main body. The top housing cap is composed of a cap and a buttress for the embedded system and battery. When the embedded system needs to be fixed or upgraded, the top housing cap is turned and pulled. Figure 6 shows the basic blueprint for the case.

The length of the main body is $266 \mathrm{~mm}$, and the diameter of each housing cap is $8 \mathrm{~mm}$. The total length of the external case is $282 \mathrm{~mm}$. The external diameter is $100 \mathrm{~mm}$, and the internal diameter is $75 \mathrm{~mm}$. Thus, the thickness of main body is $12.5 \mathrm{~mm}$. This case should be able to withstand at least 200 bars of pressure. According to the results of the structural analysis described below, this case can withstand up to 400 bars of pressure, but the case was tested at pressures up to 200 bars because the performance of the O-rings and grease could not be tested in this study.

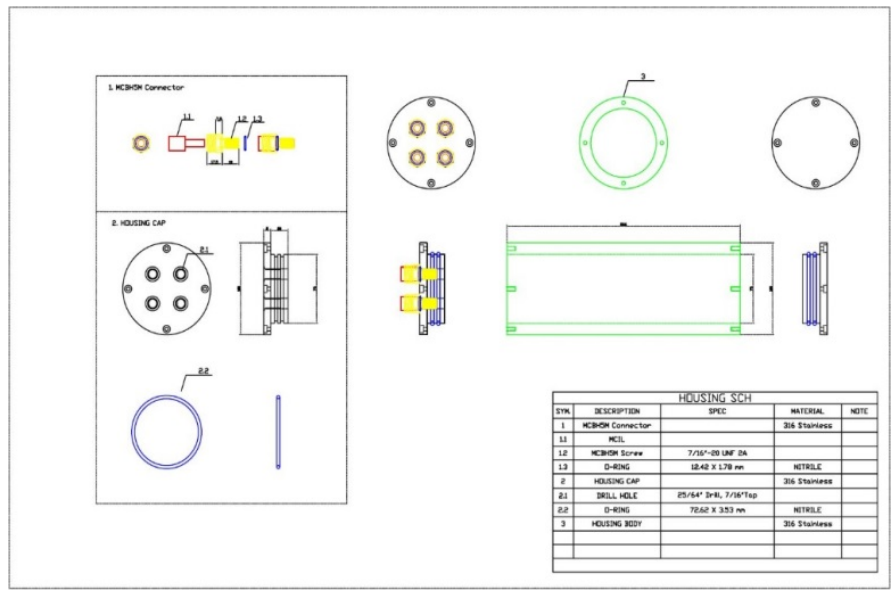

Figure 6. Basic blueprint for the external case.

Table 3. Dimensions, number of nodes, and number of elements of the finite element $(\mathrm{FE})$ model

\begin{tabular}{ccc}
\hline Dimensions $($ size $) \mathrm{mm}$ & \multicolumn{2}{c}{ FE model (tetrahedral elements) } \\
\cline { 2 - 3 }$($ length $\times$ diameter $\times$ thickness $)$ & No. of nodes & No. of elements \\
\hline $266 \times 100(\phi) \times 12.5$ & 8,195 & 40,344 \\
\hline
\end{tabular}

Table 4. Physical properties of the external case

\begin{tabular}{cccc}
\hline $\begin{array}{c}\text { Young's } \\
\text { modulus } \\
\left(\mathrm{N} / \mathrm{mm}^{2}\right)\end{array}$ & $\begin{array}{c}\text { Shear } \\
\text { modulus } \\
\left(\mathrm{N} / \mathrm{mm}^{2}\right)\end{array}$ & $\begin{array}{c}\text { Poisson's } \\
\text { ratio }\end{array}$ & $\begin{array}{c}\text { Density } \\
\left(\mathrm{kg} / \mathrm{mm}^{3}\right)\end{array}$ \\
\hline $2.1 \times 10^{5}$ & $8.07 \times 10^{4}$ & 0.3 & $7.85 \times 10^{-6}$ \\
\hline
\end{tabular}

\subsection{Structural Analysis of the Prototype}

Before manufacturing the external case of the prototype, the stability of the external case should be confirmed. To do this, a structural analysis was carried out using a finite element (FE). A FE model of the main body, a top housing cap, and a bottom housing cap made of austenitic 316 SS was developed using three-dimensional tetrahedral elements with four nodes. Orings for sealing the gaps around the main body, top housing cap, and bottom housing cap were not considered because it is not easy to determine the strength of O-rings. Table 3 shows the dimensions, number of nodes, and number of elements of the FE model. The physical properties of the external case are shown in Table 4.

Two boundary conditions, a vertically standing state and a laterally lying state, were assumed. In other words, the external case was modeled as standing perpendicular to and horizontal 
Table 5. Results of the simulation of the response of the prototype

\begin{tabular}{|c|c|c|c|c|c|c|}
\hline Condition & $\begin{array}{c}\text { Max. } \\
\text { displacement }\end{array}$ & $\begin{array}{l}\text { Part at which the } \\
\text { max. displacement } \\
\text { occurred }\end{array}$ & $\begin{array}{l}\text { Max. von mises } \\
\text { stress } \\
\left(\mathrm{N} / \mathrm{mm}^{2}\right)\end{array}$ & $\begin{array}{l}\text { Part at which the } \\
\text { max. stress } \\
\text { occurred }\end{array}$ & $\begin{array}{c}\text { Yield } \\
\text { stress } \\
\left(\mathrm{N} / \mathrm{mm}^{2}\right)\end{array}$ & $\begin{array}{l}\text { Safety } \\
\text { factor } \\
(\mathrm{D} / \mathrm{E})\end{array}$ \\
\hline \multirow[t]{3}{*}{ Vertical } & \multirow[t]{3}{*}{0.058} & \multirow[t]{3}{*}{ Top housing cap } & 163.6 & Inside of body & 235.0 & 1.44 \\
\hline & & & 171.9 & $\begin{array}{l}\text { Inside of bottom } \\
\text { housing cap }\end{array}$ & & 1.37 \\
\hline & & & 168.1 & $\begin{array}{l}\text { Inside of top } \\
\text { housing cap }\end{array}$ & & 1.40 \\
\hline \multirow[t]{3}{*}{ Lateral } & \multirow[t]{3}{*}{0.046} & ain body & 182.4 & Inside of body & & 1.29 \\
\hline & & M & 194.8 & $\begin{array}{l}\text { Inside of bottom } \\
\text { housing cap }\end{array}$ & & 1.21 \\
\hline & & & 163.1 & $\begin{array}{l}\text { Inside of top } \\
\text { housing cap }\end{array}$ & & 1.44 \\
\hline
\end{tabular}

Table 6. Specifications of the embedded system

\begin{tabular}{ll}
\hline Item & Description \\
\hline CPU & $\begin{array}{l}\text { PIC24FJ64GA106 } \\
\text { (Microchip) }\end{array}$ \\
Input & 8 Analog input, 16 bit \\
Input Range & $0-+10$ V or 4-20 mA \\
Accuracy (mV, rms) & 0.1 \\
Communication connection & RS-232, 485 \\
Memory & 8 Mb flash memory \\
Power & $\begin{array}{l}\text { External input, rechargeable } \\
\text { batteries }\end{array}$ \\
Casing materials & 316 Stainless steel \\
Connectors & Subconn connectors \\
Operating temp $\left({ }^{\circ} \mathrm{C}\right)$ & 0 to 40 \\
Pressure rating $(\mathrm{m})$ & 2000 water depth \\
ADC & LTC 2400 (linear \\
& technology) \\
\hline
\end{tabular}

with the seabed. Pressures of 50, 100, 200, 300, and 400 bars were simulated as being gradually applied to the external case. As Table 5 shows, the external case was stable under 400 bars of pressure.

\subsection{Implementation of an Embedded System}

In general, a subsea data logger system does not need to gather signals from inside the case because stability is already verified before releasing. However, it was necessary in this study to gather signals from inside the case to verify the stability of the inner embedded system. Thus, a customized embedded system was developed in this study. The specifications for the embedded system are shown in Table 6. The embedded system for the prototype is shown in Figure 7.

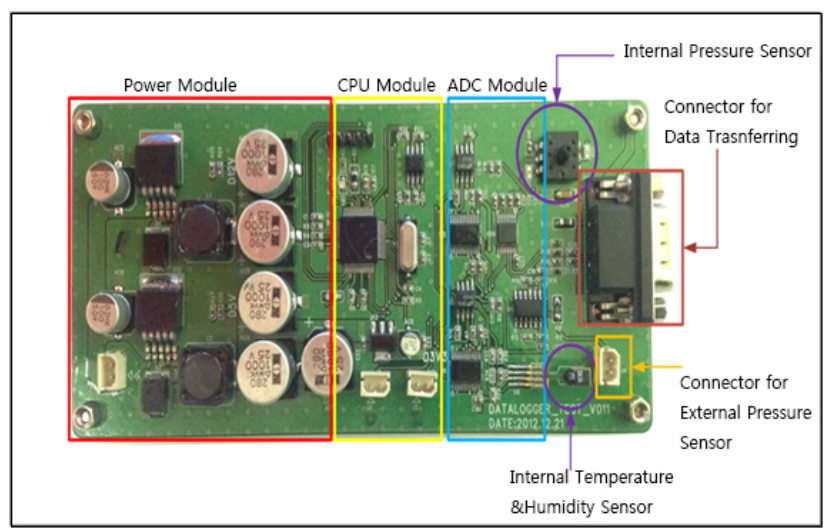

Figure 7. Embedded system for the prototype.

The embedded system uses a PA-33X manufactured by Keller to gather internal and external pressure signals, and uses an SHT75 manufactured by Sensirion to gather internal humidity and temperature signals. Figure 8 shows the embedded system that connects to the top housing cap.

\subsection{Housing Tests and Results}

The housing was tested at pressures below 200 bars to verify the stability of the external case. The testing was conducted at the Korea Research Institute of Ships and Ocean Engineering (KOSORI), using an extreme-high-pressure chamber facility. The embedded system and battery were installed together inside the case. The top housing cap was sealed and was connected to the external pressure sensors as shown in Figure 9.

Table 7 summarizes the test conditions. The test duration was 2 hours. Figure 10 shows a snapshot of the testing in the extreme-high-pressure chamber facility. 


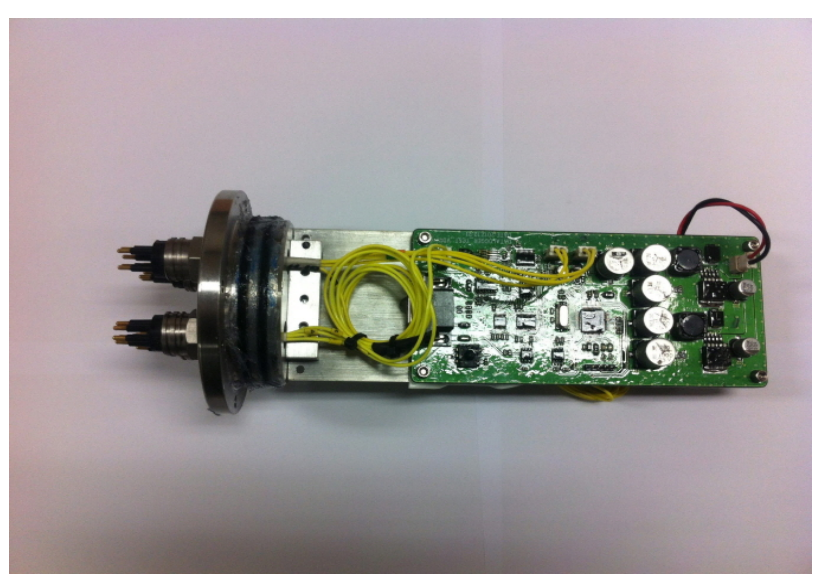

Figure 8. Embedded system connected the top housing cap.

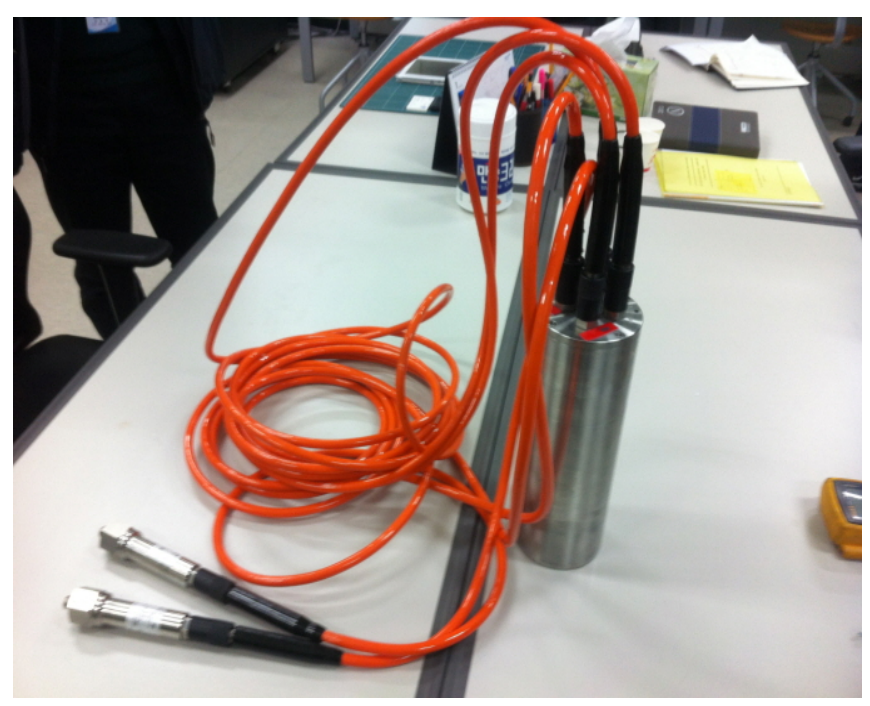

Figure 9. Prototype with external sensors.

\begin{tabular}{cccc} 
Table 7. Test conditions & Condition & $\begin{array}{c}\text { Pressure range } \\
(\mathrm{kPa})\end{array}$ & $\begin{array}{c}\text { Duration } \\
(\mathrm{hh}: \mathrm{mm}: \mathrm{ss})\end{array}$ \\
\hline No. & Pressurization & $0-5,000$ & $00: 05: 00$ \\
\hline 1 & Pressurization & $5,000-10,000$ & $00: 05: 00$ \\
2 & Pressurization & $10,000-15,000$ & $00: 05: 00$ \\
3 & Pressurization & $15,000-20,000$ & $00: 40: 00$ \\
4 & Decompression & $20,000-1,000$ & $00: 10: 00$ \\
6 & Pressurization & $1,000-20,000$ & $00: 10: 00$ \\
7 & Decompression & $20,000-0$ & - \\
\hline
\end{tabular}

After the 2-hour test was completed, the prototype was removed, and its appearance was examined. Figure 11 shows the results of the appearance examination.

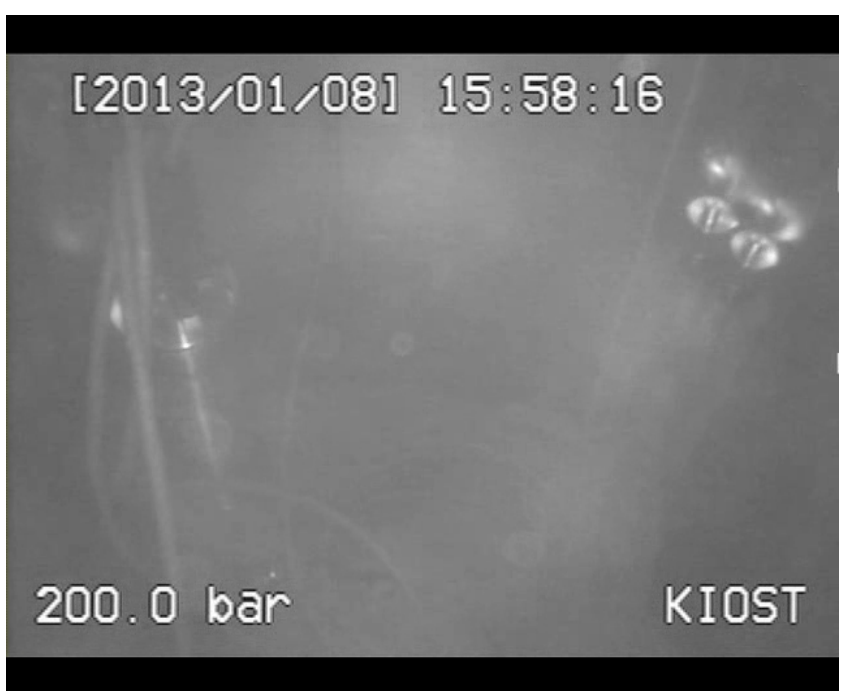

Figure 10. A snapshot of testing.

When the top housing cap was removed, no leakage was found on the embedded system or inside the case. In addition, the LED light on the embedded system was still working. This means that the embedded system appeared to works properly. To verify the performance of the embedded system, data stored data on the $8-\mathrm{Mb}$ flash memory were extracted and analyzed. Figure 11 shows the results. Figure 12 shows the results of a comparison of data on the pressure on the chamber and the pressure measured by an external sensor. No great difference was observed. The data from the temperature sensor and the humidity sensor were stored as well. The results indicate that the embedded system worked properly during the test.

During the test, the inside temperature of the prototype remained stable at between $10.8^{\circ} \mathrm{C}$ and $11^{\circ} \mathrm{C}$, a range of only $0.2^{\circ} \mathrm{C}$. This temperature range is appropriate for the operation of the embedded system. The inside humidity of the prototype remained stable at between $10.3 \%$ and $10.55 \%$, a range of only $0.25 \%$, which is an appropriate humidity range for operation of the embedded system. The inner pressure of the prototype remained 6 bars during the test. The sealing process brings about this result. The inner pressure is also appropriate for operation of the embedded system.

\section{Conclusions}

As oil consumption increases and the price of oil rises to more than $\$ 100$ per barrel as a result of the economic growth of emerging markets such as those of China and India and depletion of oil from land-based sources, oil wells in onshore, 


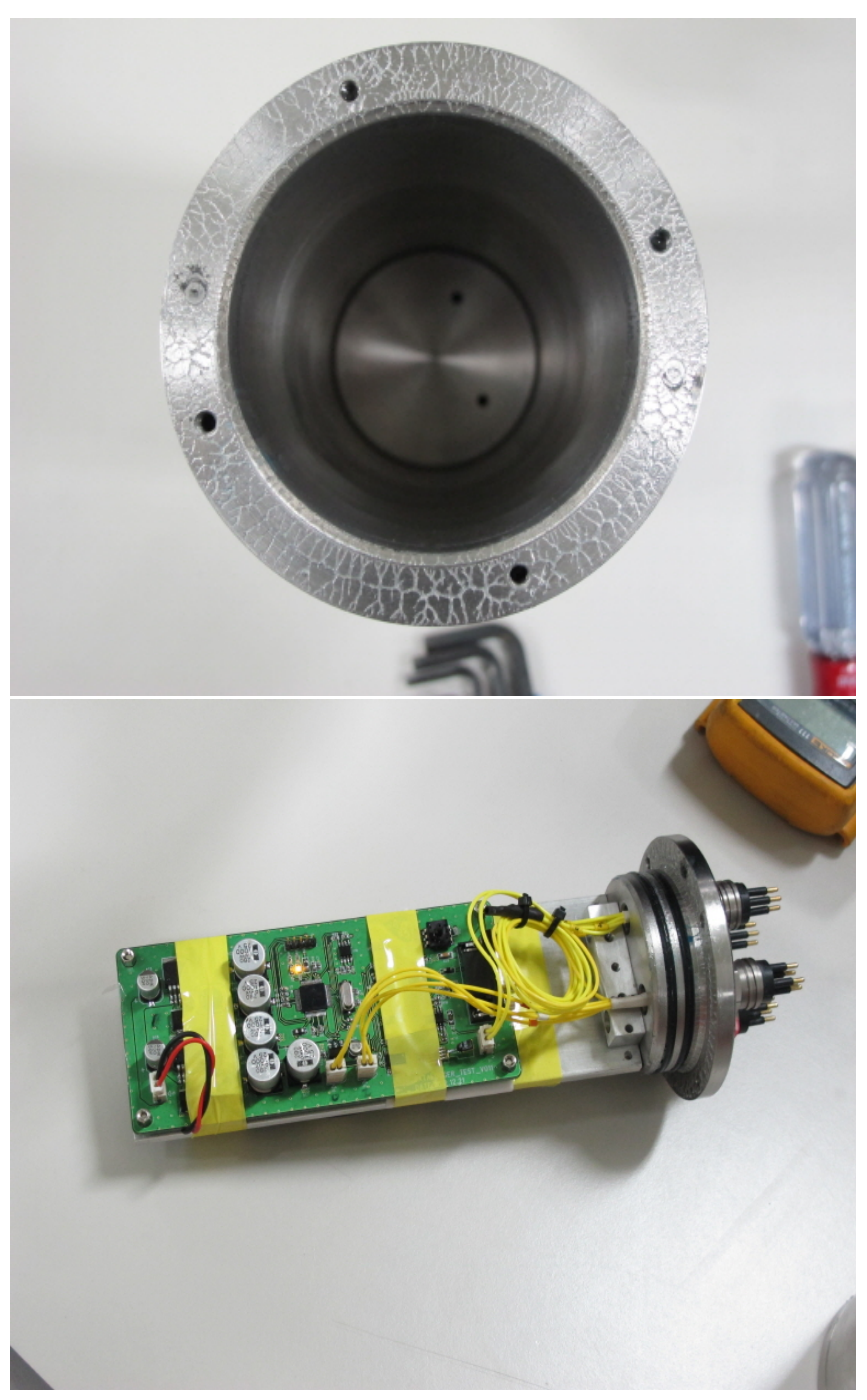

Figure 11. Appearance of prototype components.

offshore, and especially subsea areas become increasingly productive for oil companies. Because a subsea oil production system has to be operated safely for 20-30 years, the market for IRM services and subsea data logger systems will grow steadily for some time. In addition, the safety of subsea oil production will be more strictly enforced in coming years because of the accident that occurred in the Gulf of Mexico in 2010. Therefore, a Korean company that develops a subsea data logger system can have a chance to enter another blue ocean market, even though the market for subsea equipment is very conservative as other researches already succeeded $[11,12]$. Because of the extreme high pressures to which subsea equipment is subjected, many people have thought that the development of a subsea data logger system would be difficult. The results of this study demonstrate the feasibility of developing a subsea data logger

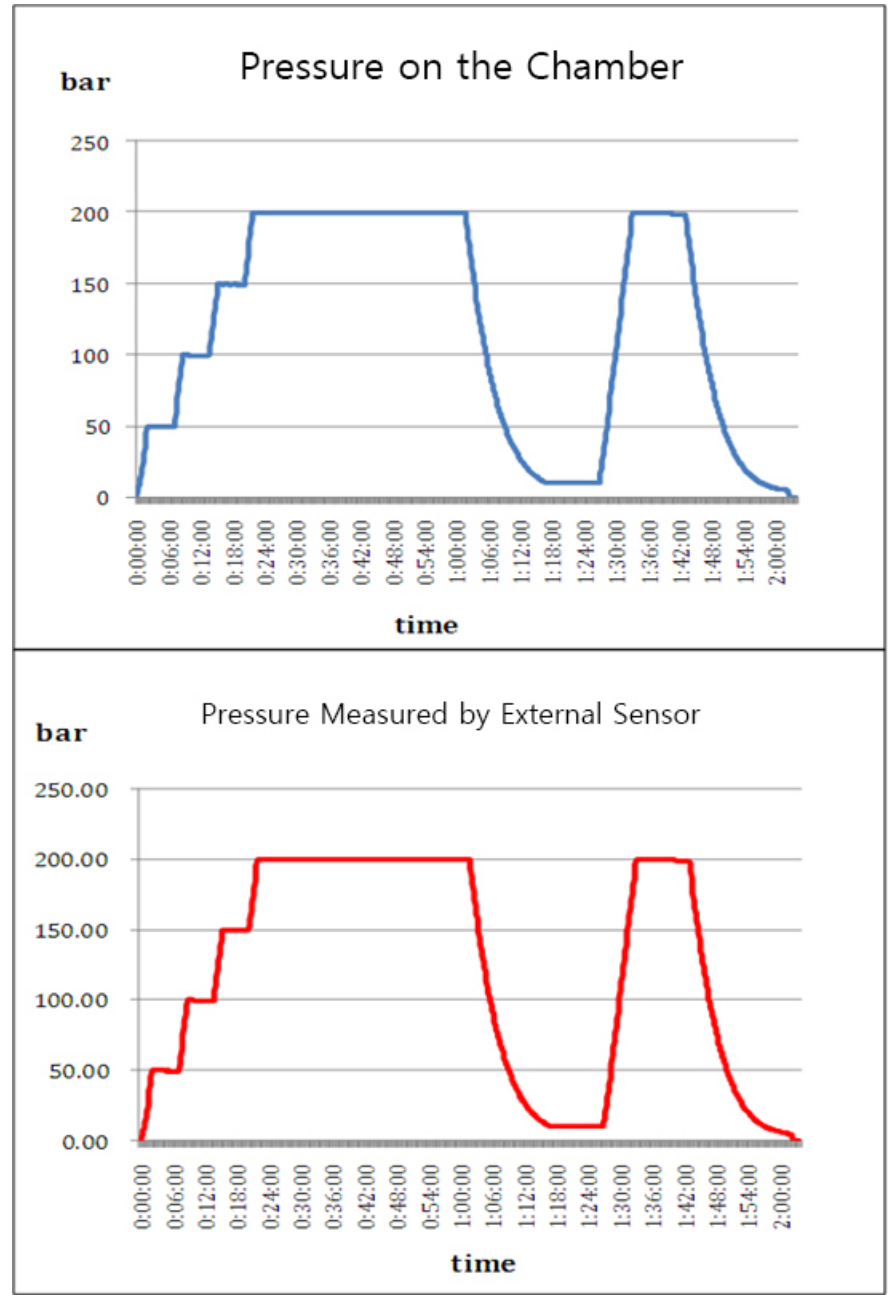

Figure 12. Results of a comparison of pressures measured on the chamber and by an external pressure sensor.

system based on the prototype described in this paper.

\section{Conflict of Interest}

No potential conflict of interest relevant to this article exists.

\section{Acknowledgements}

All authors sincerely appreciate the courtesy of TFU Co., Ltd.

\section{References}

[1] PennNet, "World trends and technology for offshore oil and gas operation," Offshore, vol. 55, 2005. Avaliable http://www.offshore-mag.com/ 
[2] British Petroleum, Deepwater Horizon Accident Investigation Report, Sep. 2010.

[3] H. S. Choi, "Review of deepwater petroleum exploration \& production," Journal of Ocean Engineering and Technology, vol. 22, no. 4, pp. 72-77, Aug. 2008.

[4] P. Damsleth, B. Abdalla, and K. C. Tang, "Challenges and concept solutions for 46-inch diameter deepwater PLEMconnector qualification," in Proceedings of the 22nd International Offshore and Polar Engineering Conference, Rhodes, Greece, June 17-22, 2012, pp. 213-221.

[5] E. H. Winther-Larssen, "Design of an electric X-mas tree gate valve actuator," M.S. thesis, Master of Science in Engineering Cybernetics, Norwegian University of Science and Technology, Norway, 2007.

[6] H. S. Choi, C. H. Do, and S. K. Lee, "Study on parameters for optimum design of integrated subsea system," Journal of the Society of Naval Architects of Korea, vol. 49, no. 4, pp. 340-349, Aug. 2012. http://dx.doi.org/10.3744/SNAK. 2012.49.4.340

[7] H. van den Boom, J. Koning, and P. A. Marin, "Offshore monitoring: real world data for design, engineering and operation," in Proceedings of the Offshore Technology Conference, Houston, TX, May 2-5, 2005.

[8] A. Mnuel, X. Roset, J. Del Rio, D. M. Toma, N. Carreras, S. S. Panahi, A. Garcia-Benad, T. Owen, and J. Cadena, "Ocean bottom seismometer: design and test of a measurement system for marine seismology," Sensors (Basel), vol. 12, no. 3, pp. 3693-3719, Mar. 2012. http://dx.doi.org/10.3390/s120303693

[9] M. Pfender and H. Villinger, "Miniaturized data loggers for deep sea sediment temperature gradient measurements," Marine Geology, vol. 186, no. 3-4, pp. 557-570, Jul. 2002. http://dx.doi.org/10.1016/S0025-3227(02)00213-X

[10] Z. Xueting, C. Ying, and G. Chunyan, "Ocean three components magnetometer for seafloor observatory," in Proceedings of OCEANS 2010 IEEE Sydney, Sydney,
Australia, May 24-27, 2010. http://dx.doi.org/10.1109/ OCEANSSYD.2010.5603842

[11] G. K. Park, K. Y. Seo, and T. H. Hong, "Development of an embedded system for ships steering gear using voice recognition module," Journal of Korean Institute of Intelligent Systems, vol.14, no.5, pp. 604-609, Aug. 2004.

[12] G. J. Jo and J. H. Lee, "Study on how to display S-57 ENCs in an embeded mobile-platform," Journal of Korean Institute of Intelligent Systems, vol.22, no.3, pp. 334-340, Jun. 2012. http://dx.doi.org/10.5391/JKIIS.2012.22.3.334

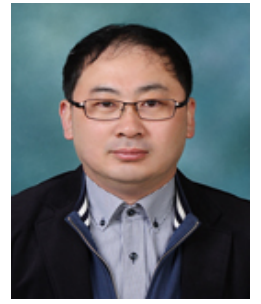

Nam-Hyun Yoo received the PhD degree in computer science from Sunchon $\mathrm{Na}$ tional University in 2007, Republic of Korea. He is a professor at Dept. of Naval Architecture, Ocean, and IT Engineering, KyungNam University. His current research interests are artificial intelligence, context awareness, ocean robots, ocean IT system, ocean embedded system, and smart sensors.

E-mail: hyun43@kyungnam.ac.kr

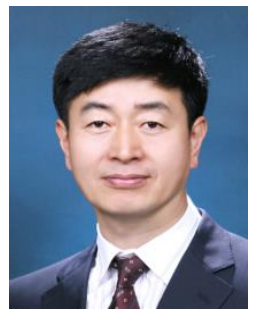

Sang-Yong Rhee received the B.S. and M.S. degrees in industrial engineering, Korea University, Seoul, Korea in 1982 and 1984, respectively and the $\mathrm{Ph} . \mathrm{D}$. degree in industrial engineering, POSTECH, Pohang, Gyeongbuk, Korea in 1992. He is currently a professor in the Division of Computer Science and Engineering, Kyungnam University, Korea. His current research interests include computer vision, neuro-fuzzy system, intelligent robot and augmented reality.

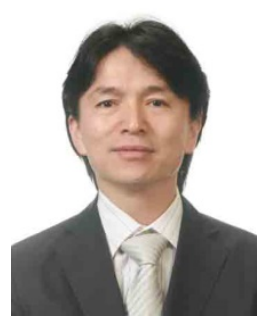

Hyeong-Ok Lee received the $\mathrm{PhD}$ degree in computer science from Chonnam National Univ. in 1999, Republic of Korea. Currently, $\mathrm{He}$ is a professor at Dept. of Computer Edu., Sunchon National Univ. His current research interests are algorithm and graph theory.

E-mail: oklee@sunchon.ac.kr 